\title{
PERSPECTIVES ON EFFECTIVE DIGITAL CONTENT \\ MANAGEMENT IN ORGANIZATIONS
}

\section{AUTHORS:}

Dr. Krishna Venkitachalam (corresponding author)

Associate Professor of Strategy

Stockholm Business School, Stockholm University, Stockholm

SE 10691, Sweden

Email: venkitachalam@gmail.com

Telephone: +468164653

\section{Dr. Rachelle Bosua}

Assistant Professor

Faculty of Management Science and Technology

Open University of The Netherlands:

6419 AT Heerlen

The Netherlands

Email: rachelle.bosua@ou.nl

Telephone: +31455762709

This is the author manuscript accepted for publication and has undergone full peer review but has not been through the copyediting, typesetting, pagination and proofreading process, which may lead to differences between this version and the Version of Record. Please cite this article as doi: $10.1002 / \mathrm{kpm} .1600$

This article is protected by copyright. All rights reserved. 


\begin{abstract}
Modern corporations face enormous digital transformation challenges in order to incorporate digital content into its corporate memory. At the same time over the last decade and a half, there is growing evidence of the advent of different types of mechanisms to manage digital organizational content. The management of digital content is particularly important to support knowledge worker practices to access, share and reuse content in knowledge intensive organizations. Despite the availability of technological solutions in the marketplace to integrate content, managers are often overwhelmed by the choices they need to make to effectively manage digital content in their organizations. Extant literature indicates that in an increasingly digitized world, there is no clear understanding of the digital content considerations for informed decision-making in organizations. Based on our research experiences in knowledge management, particularly knowledge codification in digital infrastructures we provide certain perspectives on the four considerations for effective management of digital content in large organizations. We present four short exhibits to illustrate these four core considerations which we label as the '4Cs' (i.e. content contribution, categorization, control and centralization) for effective digital content management in large organizations.
\end{abstract}

\title{
KEYWORDS
}

Content, content management, codification, digital content, knowledge transfer, knowledge management

This article is protected by copyright. All rights reserved. 


\section{PERSPECTIVES ON EFFECTIVE DIGITAL CONTENT MANAGEMENT IN ORGANIZATIONS}

\section{IMPORTANCE AND NEED FOR DIGITAL CONTENT MANAGEMENT}

Modern managers face an unprecedented growth in digital content in their organizations. This can be attributed to the proliferation of web-based technologies, the increased adoption of Web 2.0 software and broadband tools and technologies (e.g. cloud computing and workflow technologies); enabling individuals and businesses to manage content in the virtual space. In addition, some organizations are exploring ways to become 'paperless' by investing in digitization as a means to promote the sharing of, access to, and accurate, timely processing of information through the use of digital artifacts. A Gartner report published in 2016 (Gilbert et al., 2012), indicates that unstructured digital content accounts approximately $80 \%$ of the content created and stored by most companies (Kuechler, 2007; Talia, 2013). More so, a large part of digital content is stored in firm infrastructures and its growth poses significant strategic challenges to today's senior executives. One of the challenges is an organization's ability to integrate digital content into its corporate memory. This integration is vital, as a firm's organizational memory is a central underpinning for its knowledge transfer, learning 
and development (Bosua \& Venkitachalam, 2015; Spender \& Grant, 1996; Walsh \& Ungson, 1991; Wang \& Ahmed, 2003).

Over the last few years, we have witnessed the advent of different types of mechanisms, tools, and systems to manage digital content. These solutions are varied and tailored to specific purposes, users, environments and contexts of use in organizations (Dečman \& Vintar, 2013; Tian et al., 2008). It is therefore, a norm that managers are overwhelmed and confounded by the choices they need to make to invest in appropriate tools for effective management of digital content in their organizations to create business value (Williams et al., 2009). Additionally, managers repeatedly make unproductive choices by investing in content management tools that often fail to render valuable organizational outcomes. Past research indicates that in an increasingly digitized world, there is no clear understanding of the requirements to better manage digital content for informed decision-making in organizations (Rockley \& Cooper, 2012). Hence, in this article we aim to provide certain perspectives on What are the fundamental considerations for effective management of digital content in large organizations?

Informed by our research and practical experience of more than a decade associated with codification practices as a means to facilitate content capture and transfer electronically, we believe that the lessons learned from these practices can provide insightful knowledge for managers about suitable requirements to better manage digital content, particularly in large 
knowledge intensive organizations. Based on our extensive research on this topic, we include four short exhibits in the later part of this article. These exhibits illustrate four core considerations of digital content management which we label as 4Cs (i.e. contribution, categorization, control, and centralization) for effective digital content management in large organizations. We also offer some managerial viewpoints that explain the digitization of content in organizations.

\section{BACKGROUND OF CONTENT MANAGEMENT}

For a better understanding of the value of organizational content from a managerial perspective, it is useful to draw a comparison between data and content. The terms 'data' and 'content' are often used interchangeably, however, they are subtly different (Ackoff, 1989; Gammack et al., 2012). Data is a collection of characters that are devoid of human meaning when combined. For example, the number ' 82 ' (or a combination of the characters ' 8 ' and ' 2 ') may be treated as a string or a number, and in one context refer to an organization's age, but in another reference to its total number of employees. Computers are required to process data into information that has meaning within some context. Data relates to large volumes of transactions and is processed by application programs into meaningful information. Typically, in today's world of increased connectivity and digitization enabled by different computing devices and smart objects, large volumes of digital data are generated and stored in real-time requiring the need for more digital storage capacity. Transaction processing 
programs and customized applications convert digital data into information through the manipulation of data items (Gammack et al., 2012).

In contrast to data, content generally refers to information associated with the context and human meaning. The latter is often referred to as unstructured data in the form of collections of text often combined with other content types such as multi-media (Beach \& Schiefelbein, 2014; Davenport, 2013; Dallemule \& Davenport, 2017). Typical examples of content are documents, reports, web pages, or multi-media content such as sound and images or a combination of these. Content can be captured in paper or digital format created by humans or computers. In the latter instance, web servers can combine content from various sources to create new content. Digital content is usually stored in repositories and knowledge bases, web or file servers (Geisler, 2006), and needs to be stored and classified systematically to be of use to individuals and teams in the broader organizational context (Asprey \& Middleton, 2003; Lynch, 2003; Selwyn, 2009). Research has shown that digital content creation is at the heart of knowledge management and that valuable content i) facilitates learning and knowledge transfer, and ii) counteract the loss of valuable organizational knowledge (Bosua \& Venkitachalam, 2015). The process of systematically capturing, classifying and making content available for situated use, is referred to as content management and is formally defined by Smith and McKeen (2003, p. 648) as the: "the strategies, tools, processes and skills an organization needs to manage all its information assets (regardless of type) over their life cycle". 
All organizational content proceeds through four distinct life cycle stages: capture, organize, process and maintain (Smith \& McKeen, 2003). The capture stage includes activities to identify appropriate content in terms of range, quality, and depth, acquiring content from sources, and preparing and converting content for storage. The next 'organize' stage includes the use of mechanisms to arrange content into structures that facilitate the search and retrieval of content. Mechanisms include the use of tagging, meta-data, and taxonomies in combination with human skills and activities that link and inter-relate content, databases, software applications and platforms. The 'process' stage involves careful checking, sorting and analysis of content to inform decision-making and is often the most underestimated yet the most important since it derives business value from content.

Content processing capabilities can be improved through competences such as knowledge of data and the business, skills in statistical modeling, analytics and technology, and the ability to communicate findings to decision-makers that will encourage their use (Batley, 2007; Davenport et al., 2001). The final 'maintain' stage includes ongoing efforts to establish standards, principles, and mechanisms to keep existing content up-to-date and dispose of content that is no longer used. A managerial perspective would suggest every organization's approach to manage its digital content life cycle is different and depends on the unique attributes of its information technology landscape, organization structures, and content creation and use patterns. Hence, content management solutions employ different mechanisms, tools, and technologies across different organizations. 


\section{RELEVANCE OF CODIFICATION OF CONTENT}

Codification is the process of systematically converting content into an explicit form such as useful concepts, events or processes associated with a particular context in an organization. The result of this process is unstructured data that falls into the content category and can either be concise (e.g. a list of words) or more extended as a free form of unstructured text (Batley, 2007; Madden et al., 2013). Typical examples would be daily activities and associated tasks planned, set out in a specific order that aligns with actions. A set of guidelines on how to perform a recurring routine business process would constitute a more detailed exposition of unstructured text that documents the procedure as opposed to listing words that are cognitively linked to organizational actions. Codification is an inherently complex task since it requires careful thought to convert or encode one's innate or acquired experiences often enacted without thinking, into a form that others can easily follow, understand and apply in the context of organizations.

Codification can be viewed as a formal, deliberate approach to document one's experiences. Specific examples of codified content include best practices, frequently asked questions, heuristics, rules of thumb or any other form of content that captures unique individual or group experiences. Based on our extended experiences with a number of organizations, we consider 'two types of codification practices' namely informal and formal and 'two objectives of codification' namely codifying for oneself or codifying for others. Our observations revealed less effort was spent on codifying for oneself as opposed to codifying 
for others (e.g. others in the same or teams). This is because the content is intertwined with a situated context (Thompson \& Walsham, 2004; Tsoukas, 1996) and sharing with others who understand the context is far easier than sharing with those who are not familiar with the context.

Three reasons highlight why codification is an important activity of the content lifecycle in organizations. Firstly, it clarifies and frames thinking and experiences, examples include codifying steps to accurately solve a problem, requires individuals to carefully reflect on the sequence of activities and/or steps, outcomes, pre-conditions, and post-conditions associated with each business process activity. Secondly, once the organizational content is digitized, it may easily be shared and diffused within and between individuals, groups, teams, and companies using IT. Finally, once captured, codified content becomes digitized that can be searched, retrieved and re-used as a basis for new ideas and creation of new content. Moreover, digital content contributes significantly to the growth of an organization's memory system (Moorman \& Miner, 1998; Walsh \& Ungson, 1991). Developing from our research experiences, we present four exhibits related to the four considerations for effective management of digital content in large organizations in the following section.

\section{OVERVIEW OF EXHIBITS}

Our experience in content management covered more than a decade from 2003 to 2015 in which we interviewed content managers and content users. We were specifically interested in 
understanding their key considerations to manage digital content across large organizations. Our past work included a variety of organizations from multiple industry sectors that included private and government institutions. We conducted 74 interviews with participants from 25 organizations representing ten industry types: education, government, manufacturing, retail, GIS software product development, banking, telecommunications, consulting, healthcare, and research and development. Nine were multinationals while the others were from Australia and Europe. Participants included senior and middle managers of product, process and technology divisions, including intranet coordinators, and consultants responsible for websites, wikis, and blogs. We analyzed organizational artifacts to understand content management models and codification efforts in the context of knowledge management. Our interviews focused on digital content management strategy, tools used to manage content, elements codified, how digital content was managed/made available to employees. We noticed through observations that networking activities drew on digital content as a basis for collaboration, communication, and knowledge transfer. We also observed how content often replaced physical interaction and complimented problem-solving discussions. Moreover, our data collection highlighted the importance of organizing content and strategies individuals and teams drew on to improve digital content management in teams and functional units in organizations. Next, we provide four short exhibits to illustrate our perspective of digital content management considerations of $4 \mathrm{Cs}$ that we propose in this article.

Exhibit 1 - Emphasis on Content Contribution

This article is protected by copyright. All rights reserved. 
GISEng, a large multinational engineering consulting organization, provides leading enterprise engineering software solutions dedicated to processing, power and marine industries throughout the world. GISEng has its head office in the USA, and multiple worldwide offices in Asia-Pacific, Europe, the Middle East, Africa and South America. GISEng's geographical spread requires continuous collaboration between the USA head office and branch offices spread across the world. Content sharing relates to troubleshooting of hardware and software related problems of GISEng's proprietary software packages occurred through “... [content] contributions through Email Internet forums and an internal website with an issues $\log$... and anybody can answer questions...”. The success of smoothly running GISEng's many software packages relied on free content contributions from its large cohort of software engineers throughout the world.

GISEng is committed to delivering high-quality consulting services to its large set of customers. Lessons learned from old projects were most important to execute a new project work. Different project repositories were created to capture important project-related content and specific lessons learned. The organizational culture focused on individuals' contributions to content as one project manager stated: "We put everything [related to projects] on the server [in a repository] and anyone can access that... at the moment we are tracing each day what we are doing on particular issues so that other client companies can see what we are doing". One service engineer felt content contributions were useful as "You don't want to reinvent the wheel, heaps of times project stuff gets repeated across projects and development takes time, resources and a lot of money". Content contributions allowed project managers to 
"Look at previous projects that are related and if somebody has done it [a similar project] before, and knows how to do it better, we rely on each other's information [content]".

\section{Exhibit 2 - Emphasis on Content Categorization}

CouncilA, a large City Council in one of Australia's largest states, serves a customer base of more than 120,000 residents. The council provides close to a hundred services to its residents, ratepayers and community groups supporting children, adults, and senior citizens. CouncilA's service delivery varies from health and wellbeing, education and library services, family and youth services to household services including waste removal, recycling, pet and animal services. CouncilA prides itself in the delivery of high-quality services to residents and has invested in an extensive IT infrastructure that enables and supports its services and operations. To enhance service delivery and interaction with customers, CouncilA has invested in multiple social media networking tools such as Twitter, Facebook, and YouTube to promote interactions with its different stakeholders.

CouncilA experiences a vast flow of content because of constant communication between the council and ratepayers, residents and community groups. In particular, content-related items include documents, records, and social media tweets or messages that accompany applications, forms and other requests for services. Due to increases in content sharing and creation, the Council invested (in mid-2000) in an extensive document and records 
management system to manage the vast amount of content transferred and generated on a daily basis. CouncilA's decision to invest in an enterprise-wide document and records management system aimed to align content artefacts with CouncilA's workflow activities of each functional unit. A major decision was taken to classify content into categories that could be linked to each of the council's twenty-five core functional units that include 'for instance' health and local laws, statutory planning, aged and disability services and financial services.

Content categorization introduced a logical connection between functional units, digital content sharing, and workflow, which greatly expedited CouncilA's service delivery. For example, incoming communications related to service requests could immediately be channeled to and associated with the responsible functional unit while the unit itself could act quicker upon requests in the allowed time frame allocated to each type of workflow. This process enhanced the communication between customers and service units creating greater transparency in terms of task completion for service delivery. The senior content and records manager was instrumental in creating the content categories and indicated the value of content categorization saying: "We can now classify all incoming correspondence such as email, letters and documents and we use these reference parts or keywords as categories right through the organization. All content is then stored in a hierarchical structure based on classification [for categorization] in the repository. This structure was predetermined before we implemented the content system. Each service direction knows exactly when to action any incoming mail with its accompanying documents". 
The manager indicated their categorization scheme was useful to link specific roles in functional units to content, "So if I go into the 'journal' it tells me that a new request came in (recorded by me) and I can set in the correspondence cell PersonA's initials and it's automatically sent by email to Wilken the coordinator. He gets it [the request and accompanying content] and just clicks on it to action. So we created a category of what it's all about and a service direction that then goes to the relevant service unit and tells them what they need to take action on whatever issue". Further, the manager indicated that the categories of content allowed CouncilA to streamline its operations and service delivery to its large customer base while improving collaboration and networking among employees because "... people can [now] find content straight away and three or four people can share and access content at the same time”.

\section{Exhibit 3 - Emphasis on Content Control}

MedManufact, specializing in the manufacturing of green containers to recycle medical waste, is a large multinational corporation, with a presence in Australia, UK, and the USA. For the past twelve years, MedManufact uses multiple Wiki repositories that serve as a collaborative framework to manage its large content base. The use of wikis has been most useful allowing MedManufact to capture and transfer content for both collaboration, 
communication, and learning. The organization is focused on maintaining and documenting key procedures used throughout MedManufact so that different procedures can be aligned across all the different countries. As a result, MedManufact has multiple project-related repositories that are extended regularly as new projects emerge.

MedManufact realized over the past decade that digital content management is instrumental in maintaining operations at times of high staff turnover while repository content also fostered learning, especially for newcomers. While content is made widely available to MedManufact employees, access to wiki content is strictly controlled using different wiki space types. The content manager indicated "There is a private and public space for each division and the public space is where employee put as much of their content as they possibly can, but the private space is where very specific confidential information [content] is held that you don't want people to access". While MedManufact encourages content contributions as much as possible, the organization was also conscious that "There is sort of areas that one has to be careful about, obviously like meeting minutes. So there are areas that need to be locked down [for some users]. We [management] decide on levels of access, who should have access. That really helps us build our taxonomy of what goes on where”.

Exhibit 4 - Emphasis on Content Centralization

This article is protected by copyright. All rights reserved. 
EducoIT is an IT helpdesk in a large academic institution serving a large community of science students. EducoIT provides programming and other technical support to staff and students and the helpdesk is staffed by a team of technical support staff who work in shifts over the course of each weekday. Each shift is between 5 and 8-hours long with up to two staff members at the helpdesk counter at times. Helpdesk-related work occurs either face to face or through the logging of helpdesk requests. Due to high mobility and movement of shift staff during the day, the helpdesk manager created a Helpdesk website with FAQs and other key information individuals require setting up, run or use specific software packages and shared content space. The shared digital spaces serve as a central container of key content, all the helpdesk staff need to know as they start their shifts.

All content related to an individual's shift work, i.e. problems experienced, solved and unresolved, are documented and stored centrally in this artifact. This artifact facilitated communication and collaboration between all the shift workers in two ways. Firstly, the central availability of content allowed all shift workers access to digital content from anywhere via a website. Secondly, the availability of centralized digital content meant that all shift workers were on the same page in terms of aspects and issues that were related to helpdesk operations. One shift worker commented, "information is at my fingertips", which simplified his work significantly. 


\section{CHALLENGES IN DIGITAL CONTENT MANAGEMENT}

Our research experiences with organizations that include the above presented short exhibits on codification activities and the accompanying management of digitized content, revealed certain challenges. Informed by codification problems related to content transfer, we suggest three challenge areas that influence digital content management:

\section{Creating and capturing content:}

While it is relatively easy to create digital content for oneself, it is more difficult to create content that others can use. Content is often not created from a user perspective for an audience or a specific context. EducoIT had to carefully design solutions to capture content in useful formats and categories that could be used (and reused) by shift workers. In addition, file servers and other content 'containers' are often depleted with unusable content resulting in inefficient usage of mass storage. Hence, content containers become 'junkyards' of information in no time. From a management perspective, limited guidelines are given in terms of the creation and capturing of content and long-term content re-use intentions. Whereas, MedManufact had to ensure that essential digital content was codified, captured and stored into specific repositories for authorized access.

Access and use of digital content:

This article is protected by copyright. All rights reserved. 
Content is often unavailable to those who can directly benefit from it. Moreover, search and retrieval activities do not render the required results often due to the lack of skills and tools to search content, inappropriate categorization of content and accompanying use of technologies for accomplishment. This was visible in GISEng where content was not transferred with the right teams. In addition, pushing content to specific users may also fail. Users often indicate that they are not aware of existing content and would often 'redo' key activities, which could have been done more easily if they had access to useful content. Also, content 'containers' are frequently set up preventing access to required content areas excluding specific users' access. A GISEng manager indicated these limitations as Sales Engineers created content, while Project Managers were unaware of it. In contrast, content segregation was necessary for MedManufact to prevent newcomer's access to confidential content. Sometimes search and retrieval activities may yield content in a format that cannot be readily used but require some reworking activities that may discourage content use (as in the exhibit for GISEng's discussion forums in cases where there is lengthy feedback on problems).

\section{Management of digital content:}

Users are rarely notified of updates or changes to digital content while irregular updates render obsolete or outdated content if not managed properly. There seem to be no 'gatekeeping' roles to manage content on levels higher than the user level, while overall plans and standards to manage organizational content were absent. Both CouncilA and GISEng suffered these problems and managers complained that the exponential growth in content got out of hand necessitating the adoption of specific tools to better manage content. In all the 
exhibits, it is worth highlighting that there is the absence of regular content assessment activities to determine its value in the broader organizational context.

\section{PERSPECTIVES ON DIGITAL CONTENT MANAGEMENT}

The growth in and management of digital content adds new challenges to organizations as they need to transform their existing organizational processes and practices to integrate and exploit new digital technologies (Hess et al., 2016). These challenges can be addressed from different perspectives that can be useful to highlight the aspects that need to be covered in digital content management initiatives. From a strategic perspective, the organization's focus is mainly on guidelines regarding how the organization's digital content will be managed and implemented over the short, medium and long-term. This includes different strategic approaches to content management that incorporate content management policies and standards, the overall culture, and orientation towards digital content management, roles responsibilities, structures and tools to manage content, ways in which content can be classified/categorized and searched. The enterprise-wide digital content management strategy should form part of the organization's overall information technology strategy and be clearly articulated along with relevant performance measures (Batova \& Anderson, 2016; Rockley \& Cooper, 2012). The type of organization will determine the digital content strategy choice.

Informed by our research experiences, a large educational institution such as a university (for example, EducoIT) will need to clearly articulate its organization-wide content management strategy. An integrated centralized view towards digital content management may be the best 
strategic approach to manage content that is available in organizations' infrastructures. Senior staff or champions from the organization such as CTOs, CKOs or CIOs, business intelligence staff or roles that can link content management with organizational data warehouses and databases may need to be included to support the overall organizational digital content strategy. In contrast, software development organizations may follow a distributed strategy to digital content management by assigning content management responsibilities to each project developed within the organization (Batova \& Anderson, 2016). Specific roles such as content authors, content publishers, content and business quality managers, records managers or system specialists would be responsible for each project's content in terms of governance, categorization, and management of project-related content. Smaller organizations may follow an emergent digital content management strategy where individual team members or workers self-assign specific roles to each manage their own content.

Coming to the managerial perspective, the emphasis is on making the connection of a strategy to the individual employee. This allows interactions with employees to ensure that organizational content is constantly renewed or updated, and that policies and standards defined in the digital content management strategy are implemented (Batova \& Anderson, 2016). Project and functional level managers will help to determine the actual processes, activities, and workflows that need to be put in place to manage the full content management life-cycle from creation to content retrieval at a team or divisional unit level. Managers should determine the value they wish to gain from content and aim to instill practices to capture rich content accordingly. Additionally, digital content management activities and procedures need to be verified and evaluated regularly to determine its success. Managers 
should devise mechanisms and schemes to reward content contributors of useful content. Specialized roles such as content analysts may need to be created to come up with best solutions to manage digital content at the functional unit or group level. As an illustration, a manager of the requirements modeling unit of a software development firm may need to come up with an effective categorization scheme (for example, MedManufact) to classify content and determine the points at which digital content needs to be captured, the format to capture content and naming conventions to be used.

Managers may also need to include incentives and appraisal schemes to encourage individuals to contribute or share content within the team (Kankanhalli et al., 2005; Xy \& Li, 2015). For example, the codification of best practices might facilitate learning, knowledge transfer and mentoring processes, while the reuse of best practices might set a shared minimum standard or a baseline that can be used in consulting practices. The transfer of these content 'assets' might also draw teams of workers together around codification practices that can be reused over time. This eliminates the need for individuals to reinvent the wheel when troubleshooting or solving complex problems. In addition, shared codification practices might increase contextual quality over time (Fillieri \& Willison, 2016).

Moving to an employee's perspective, it depends on each individual's actions to manage the contributions of digital content (for example, GISEng), effectively. It involves mechanisms to ensure that each employee is applying content management principles and practices as determined strategically or within a functional unit or team. Yet, individual content 
preparation and the use of templates and categorization schemes to contribute content and different tools, applications or systems to be used, are important. Adequate training programs need to be part of an individual's working environment, while work processes should be designed in such a way that content preparation, contribution, and use form an integral part of each process (Paivarintha \& Munkfold, 2005; Smith \& McKeen, 2003). Individual users, through their work and use of digital content, identify search criteria and patterns of content use. These elements feed back into the managerial/team level and ultimately affect the principles, standards, guidelines, and policies that managers define for effective digital content management in organizations.

In the end, digital infrastructure determines the various tools, applications, and systems that support the content management activities throughout the organization (Paivarinta \& Munkvold, 2005). Specifically, the infrastructure should reflect the strategic perspective of the organization, since the digital content management strategy needs to align with the infrastructure portfolio or choice of technologies to manage digital content. Due to the emerging nature of technologies, it is strategically essential to decide on which specific technologies can adaptively align to the individual organization's context of managing digital content. A centralized digital content strategy can seamlessly integrate different content management tools and applications with existing systems in the organization such as ERP systems, Financial Management Systems, Supply chain and Customer Relationship Management systems. Another important aspect is that the organization's information infrastructure needs to be scalable, flexible and extensible to meet current and future growth 
demands and need to consider security, communication, backup and recovery, migration and monitoring aspects.

\section{FINAL CONCLUSIONS}

Content can be an invaluable organizational 'asset' if managers in organizations raise awareness of the importance of digital content in their organizations, but more specifically, concentrate awareness efforts towards improving their organization's digital content management. A key aspect that contributes to this awareness is a deeper understanding of the content lifecycle and the relevance of 'codification'. Decisions on what needs to be codified is an essential part of an organization's knowledge management strategy to improve knowledge codification processes (Bosua \& Venkitachalam, 2015) that can be an important aspect of the organization's digital infrastructure. We suspect that a deeper understanding of content and its lifecycle will also direct managers' attention to the contextual value of digital content and how content relates to specific organizational processes and workflow. To support relevance to practice, we provide pertinent managerial implications to foster effective digital content management in organizations.

When it comes to employees, there are certain implications and they include embedding codification routines in the workflow and business processes, setting up structures and metadata, taxonomies that should result from a negotiation between team members, developing codification templates and benchmarks, and finally identifying appraisal mechanisms for individuals and teams that contribute meaningful content/context to the organization's 
information infrastructure. In this context, the requirement of each employee's 'content contributions' becomes indispensable in the organization (i.e. exhibit one emphasizes content contribution). Without individual contributions, the organization cannot progress with effective content digitization in the long-term. From an infrastructure aspect, it is essential to consider the adoption and use of appropriate technologies/platforms for digital content classification. This calls for proper 'content categorization' of large amounts of digital organizational content or codified knowledge (i.e. exhibit two highlights categorization) (Geisler, 2006), and making sure there is the robust integration of different technologies that are adopted and mechanisms that drive the development of training programs pertaining to new technology use in organizations.

Furthermore, executives could consider where to appoint and manage content gatekeepers that monitor content updating and renewal, define governance principles, promote content communications and reminders, enable dynamic availability of the right content to the right people, setting permissions at an appropriate level (e.g. read and change access authorizations) and establish a content rating mechanism (i.e. frequency and quality of usage). From a managerial perspective, the consideration of 'content control' becomes pertinent and significant for effective digital content management (i.e. relevance of exhibit three highlights content control). Lastly, we suggest managers can consider certain practical implications that includes establishing an effective digital content management approach or strategy for their organization, positioning the requirement of 'centralization' to align with codification, development of $\mathrm{CM}$ artefacts and capability training (designing training 
programs that enable the effective use of digital content). Finally, it is important to implement the consideration of content centralization (i.e. a useful illustration is exhibit four on centralization) that can be suitably aligned to the nature, type and level of operations of the organization.

In summary, a greater awareness of and attempts to better manage digital content may also support organizations in their choice of selecting and customizing enterprise content management tools or to develop supportive tools for enterprise content management. This emphasizes the need to invest in relevant digital technologies as an essential part of the enterprise architecture as automated content-driven business processes are becoming more prevalent. Even so, the mobility of content is becoming more critical as more workers are mobile and workers increasingly draw on smart phones and mobile devices to manage digital content. In fact, the prevalence of big data, the cloud, and mobility in combination with more sophisticated data mining algorithms allows for seamless access to accurate content for improved decision-making. We predict that the application of the proposed four content management considerations (4Cs) i.e. contribution, categorization, control, and centralization, can foster effective digital content management, which will significantly improve the management of and access to organizational digital content in years to come. In addition, knowledge workers may benefit significantly from effective digital content management to support their work in knowledge intensive organizations. Organizations are therefore compelled to leverage their content through appropriate and cautious considerations of content digitization as proposed and explained in this article. 


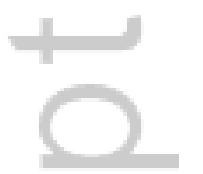

4 


\section{REFERENCES}

Ackoff, R. L. (1989). From Data to Wisdom. Journal of Applied Systems Analysis, 16, 3-9.

Alalwan, J.A., \& Weistroffer, H.R. (2012). Enterprise content management research: a comprehensive review. ECM research, 25(5), 441-451. DOI:10.1108/17410391211265133

Asprey, L., \& Middleton, M. (2003). Integrative Document and Content Management:

Strategies for Exploiting Enterprise Knowledge. Retrieved from UK.

Batley, S. (2007). The I in information architecture: the challenge of content management, Aslib Proceedings, 59(2), 139-151. DOI: 10.1108/00012530710736654

Batova, T., \& Anderson, R. (2016). Introduction to the Special Issue: Content Strategy - a Unifying Vision, IEEE Transactions on Professional Communication, 59(1), 2-6. DOI:

Beach, C., \& Schiefelbein, W.R. (2014). Unstructured data: How to implement an early warning system for hidden risks. Journal of Accountancy, 217(1), 46-51.

Blumberg, R., \& Atre, S. (2003). The problem with unstructured data. DM Review. 13, 42-46. Retrieved from http://www.dmreview.com

Bosua, R., \& Venkitachalam, K. (2015). Fostering Knowledge Transfer and Learning in Shift Work Environments. Knowledge and Process Management, 22(1), 22-33. DOI: 10.1002/kpm. 1456

Davenport, T., Harris, J., De Long, D. and Jacobson, A. (2001). Data to knowledge to results: Building an analytic capability. California Management Review, 43(2), 117-138. DOI: $10.2307 / 41166078$

Davenport, T. (2013). Analytics 3.0. Harvard Business Review, 91(12), December, 65-72.

Dallemule, L., \& Davenport, T. (2017). What's your data strategy? Harvard Business Review, 95(3). May-June, 112-121.

Dečman, M., \& Vintar, M. (2013). A possible solution for digital preservation of egovernment: A centralised repository within a cloud computing framework. Aslib Proceedings, 65(4), 406-424. DOI: 10.1108/AP-05-2012-0049

Fillieri, R., \& Willison, R. (2016). Antecedents of knowledge sourcing from a knowledge repository in the virtual product prototyping: the role of knowledge and system quality dimensions, Knowledge and Process Management, 23(2), 147-160, 
DOI: $10.1002 / \mathrm{kpm} .1512$.

Gammack, J., Hobbs, C. and Pigdon, D. (2012). The Book of Informatics. 2nd edition, Cengage Learning, Australia.

Geisler, E. (2006). A taxonomy and proposed codification of knowledge and knoweldge systems in organizations. Knowledge and Process Management, 13(24), 285-296. DOI: $10.1002 / \mathrm{kpm} .265$.

Gilbert, M. R., Shegda, K.M., Chin, K., Tay, G., and Koehler-Kruener, H. (2010). Gartner Magic Quadrant for Enterprise Content Management. Gartner Report: Published 31 October 2016, ID. G00293563.

Hess, T., Matt, C., Benlian, A., and Weisböck, D. (2016). Options for Formulating a Digital Transformation Strategy. MIS Quarterly Executive, 15(2), 123-139. DOI:

Kankanhalli, A., Tan, B. C., and Wei, K. K. (2005). Contributing knowledge to electronic knowledge repositories: an empirical investigation. MIS quarterly, 113-143.

Kuechler, W. L. (2007). Business Applications of Unstructured Text. Communications of the ACM, 50(10), 86-93. DOI: 10.1145/1290958.1290967

Lynch, C. A. (2003). Institutional repositories: essential infrastructure for scholarship in the digital age, Portal: Libraries and the Academy, 3(2), 327-336.

DOI:10.1353/pla.2003.0039

Madden, A. M., Ruthven, I. and McMenemy, D. (2013). A classification scheme for content analyses of YouTube video comments. Journal of Documentation, 69(5), 693-714. DOI: 10.1108/JD-06-2012-0078

Moorman, C., \& Miner, A. S. (1998). Organizational improvisation and organizational memory. Academy of Management Review, 23(4), 698-723.

Paivarinta, T., \& Munkvold, B. E. (2005). Enterprise Content Management: An Integrated Perspective on Information Management, Proceedings of the 38th Hawaii International Conference on System Sciences, Hawaii.

Rockley, A., \& Cooper, C. (2012). Managing Enterprise Content: A Unified Content Strategy, New Riders, Berkeley, CA.

Selwyn, N. (2009). The digital native - myth and reality. Aslib Proceedings, 61(4), 364-379. DOI:10.1108/00012530910973776. 
Smith, H. A., \& McKeen, J. D. (2003). Developments in Practice VIII: Enterprise Content Management. Communications of the Association for Information Systems, 11, 647-659. Retrieved from: Available at: http://aisel.aisnet.org/cais/vol11/iss1/33

Spender, J. C., \& Grant, R. (1996). Knowledge and the firm: Overview. Strategic Management Journal, 17, 5-10. DOI: 10.1002/smj.4250171103

Talia, D. (2013). Clouds for scalable big data analytics. Computer, 46(5) 98-101. Retrieved from: https://mycomputer.computer.org/csdl/mags/co/2013/05/mco2013050098.pdf

Thompson, M., \& Walsham, G. (2004). Placing knowledge management in context. Journal of Management Studies, 41(5), 725-747. DOI: 10.1111/j.1467-6486.2004.00451.x

Tian, X., Martin, B. and Deng, H. (2008). The impact of digitization on business models for publishing: Some indicators from a research project. Journal of Systems and Information Technology, 10(3), 232-250. DOI: 10.1108/13287260810916934

Tsoukas, H. (1996). The firm as a distributed knowledge system: a constructionist approach. Strategic Management Journal, 17(S2), 11-25. DOI: 10.1002/smj.4250171104

Walsh, J. P., \& Ungson, G. R. (1991). Organizational memory. Academy of Management Review, 16(1), 57-91. DOI: $10.2307 / 258607$

Wang, C. L., \& Ahmed, P. K. (2003). Organisational learning: a critical review. The learning organization, 10(1), 8-17. DOI: 10.1108/09696470310457469

Xu, B., \& Li, D. (2015). An empirical study of the motivations for content contribution and community participation in Wikipedia. Information \& Management, 52, 275-286. DOI: 10.1016/j.im.2014.12.003

Williams, P., John, J.L. and Rowland, I. (2009). The personal curation of digital objects: A lifecycle approach. Aslib Proceedings, 61(4), 340-363. DOI:

10.1108/00012530910973767 


\section{University Library}

\section{- M M I N E R VA A gateway to Melbourne's research publications}

Minerva Access is the Institutional Repository of The University of Melbourne

Author/s:

Venkitachalam, K;Bosua, $\mathrm{R}$

Title:

Perspectives on effective digital content management in organizations

Date:

2019-01-01

Citation:

Venkitachalam, K. \& Bosua, R. (2019). Perspectives on effective digital content management in organizations. Knowledge and Process Management, 26 (3), pp.202-209. https://doi.org/10.1002/kpm.1600.

Persistent Link:

http://hdl.handle.net/11343/286806 